\title{
Composição centesimal e perfil de ácidos graxos da carne de novilho precoce alimentado com lipídios protegidos
}

\author{
Centesimal composition and fatty acids profile of veal calves fed protected lipids
}

Ivy Scorzi Cazelli PIRES ${ }^{1 \star}$, Gilberto Paixão ROSADO², Neuza Maria Brunoro COSTA², Josefina Bressan Resende MONTEIRO ${ }^{2}$, Rosana Silva OLIVEIRA ${ }^{2}$, Soraya Maria Palma Luz JAEGER ${ }^{3}$, Denise Machado MOURÃO ${ }^{4}$

\begin{abstract}
Resumo
É crescente a preocupação da população em ingerir dietas mais saudáveis, mantendo adequado o nível de colesterol plasmático, com conseqüente redução na incidência de doenças cardiovasculares. O objetivo deste estudo foi avaliar a composição centesimal e o perfil de ácidos graxos da carne de novilho precoce de quatro grupos genéticos: Nelore (R1), Nelore x Canchin (R2), Nelore x Limousin (R3) e Nelore x Aberdeen Angus (R4), alimentados com dieta normal (D1) ou por outra constituída por lipídios protegidos (D2). Determinaramse os teores de umidade, proteína, lipídios totais, resíduo mineral fixo e o perfil de ácidos graxos. Não foram encontradas diferenças para os teores de umidade, proteína, lipídios totais, Ácidos Graxos Saturados (AGS) e Ácidos Graxos Monoinsaturados (AGMI). A dieta protegida ocasionou aumento do teor total de Ácidos Graxos Poliinsaturados (AGPI), quando comparada à D1. Por sua vez, animais que receberam D1 apresentaram maior teor de AGPI w-3 que os da D2. Verificou-se que as técnicas de nutrição animal utilizadas neste estudo garantiram um produto com maior teor de AGPI, característica esta desejável na saúde humana. Fazem-se necessários novos estudos, utilizando-se modelos experimentais, para que sejam avaliados os efeitos da carne de novilho precoce na colesterolemia.
\end{abstract}

Palavras-chave: carne bovina; ácidos graxos; composição centesimal.

\begin{abstract}
Nowadays, the concern about ingesting healthier diets, maintaining adequate plasma cholesterol level, and consequent reduction on the incidence of cardiovascular diseases has been growing. The main objective of this study was to evaluate the centesimal composition and the fatty acids profile of calves of four different genetic groups: Nelore (R1), Nelore $x$ Canchin (R2), Nelore x Limousin (R3), and Nelore $x$ Aberdeen Angus (R4), fed basal diet (D1) or a diet with protected lipids (D2). No differences were observed for the contents of moisture, protein, total lipids, saturated fatty acids, and monounsaturated fatty acids. The protected diet resulted in an increase in the content of total polyunsaturated fatty acids when compared to D1. However, the animals fed with D1 showed higher AGPI w-3 content than those fed with D2. It was observed that the current techniques of animal nutrition and production guarantee a product with smaller lipid content and higher total AGPI content, desirable characteristic for the human health. Further studies should be carried out to evaluate the effects of veal calves besides using other experimental models to evaluate the effects of calves on the cholesterolemy.
\end{abstract}

Keywords: beef; fatty acids; centesimal composition.

\section{Introdução}

A carne possui elevado teor nutritivo, sendo fonte de proteína de alto valor biológico, ferro hemínico, vitaminas do complexo B, zinco e magnésio. No entanto, existem outros fatores que restringem o consumo de carne pela população, como o seu elevado custo e a associação de sua ingestão com problemas cardiovasculares e obesidade (COSGROVE; KIELY; FLYNN, 2001).

É de interesse do consumidor que os produtos de origem animal apresentem menor teor de lipídios totais, ácidos graxos saturados e calorias e maior teor de Ácidos Graxos Monoinsaturados (AGMI) e Ácidos Graxos Poliinsaturados (AGPI), promovendo assim um padrão de vida saudável e prevenindo o desenvolvimento de doenças cardiovasculares (STIPANUK, 2000; TEIXEIRA, 2003).

É muito importante que os profissionais de saúde conheçam o perfil de ácidos graxos da carne, principalmente diante das novas tendências no desenvolvimento de alimentos mais saudáveis. Atualmente é possível alterar a composição em ácidos graxos das carnes, utilizando recursos do melhoramento genético e técnicas de nutrição animal. Segundo De La Torre et al. (2006) e Schmid et al. (2006), três fatores podem interferir na qualidade

\footnotetext{
Recebido para publicação em 23/5/2007

Aceito para publicação em 19/10/2007 (002551)

Departamento de Nutrição, Universidade Federal dos Vales do Jequitinhonha e Mucuri - UFVJM, Rua da Glória, 137, CEP 39100-000, Diamantina - MG, Brasil,

E-mail: ivycazelli@yahoo.com.br

${ }^{2}$ Departamento de Nutrição e Saúde, Universidade Federal de Viçosa - UFV, Viçosa - MG, Brasil

3 Universidade Federal da Bahia - UFBA, Cruz das Almas - BA, Brasil

${ }^{4}$ Departamento de Ciência e Tecnologia de Alimentos, Universidade Federal de Viçosa - UFV, Viçosa - MG, Brasil

${ }^{*}$ A quem a correspondência deve ser enviada
} 
e na composição da carne produzida: a ração utilizada, a raça ou cruzamento genético, e a idade em que o animal é abatido.

O melhoramento genético propicia um abate precoce, anterior ao período de deposição de tecido adiposo pelo animal, através da seleção e cruzamento de grupos genéticos específicos (JIMÉNEZ-COLMENERO; CARBALLO; COFRADES, 2001). Segundo a Associação Brasileira de Novilho Precoce (ABNP), a idade dos animais abatidos precocemente é de no máximo 24 meses, sendo que para os novilhos e machos não castrados o peso deve ser maior que $200 \mathrm{~kg}$, e para as fêmeas maior que 180 kg, Segundo Abularach, Rocha e Felício (1998), no Brasil, três quartos do gado de corte são zebuínos, basicamente Nelore e seus cruzamentos.

Por sua vez, as técnicas de nutrição animal podem contribuir para o aumento do teor de AGPI e AGMI em carnes bovinas. Segundo Anderson, Lauderdale e Hike (1986) e Bonanome e Grundy (1988), a carne bovina apresenta um baixo teor de AGPI quando comparada às carnes de frango (peito) e peixe. Entretanto, é possível se obter mudanças pela suplementação da dieta dos animais com fontes de AGPI e AGMI. Porém, é necessário que esses ácidos graxos sejam fornecidos na ração de forma protegida, uma vez que os microrganismos do rúmen, por um processo de biohidrogenação, convertem os AGI em saturados, por possuirem menor grau de toxidade ao rúmen (PALMIQUIST, 1991).

O objetivo deste estudo foi avaliar o efeito da dieta com lipídios protegidos sobre a composição centesimal e o perfil de ácidos graxos da carne de quatro diferentes grupos genéticos de novilhos abatidos precocemente.

\section{Material e métodos}

Foram utilizadas amostras de carne de novilhos não castrados precoces abatidos com 18 meses, provenientes do Instituto Melon de Estudos e Pesquisas - Silvânia - Goiás. As combinações foram originadas dos grupos genéticos: Nelore (R1), F1 meio-sangue Nelore $x$ Canchin (R2), F1 meiosangue Nelore $x$ Limousin (R3) e F1 meio-sangue Aberdeen Angus $x$ Nelore (R4), alimentados com dieta composta por lipídios de origem vegetal sem proteção (D1) e outra (D2) constituída por lipídios protegidos (sal cálcico de ácidos graxos da soja - LAC 100, produzido pela Yakult (2000), por um período de 166 dias. Os Quadros 1 e 2 apresentam os ingredientes e a composição química centesimal das dietas utilizadas, respectivamente. Foram utilizadas como controle amostras de carne bovina da raça Nelore (R1).

As amostras foram coletadas após extração do contrafilé entre a $9^{\mathrm{a}}$ e a $11^{\mathrm{a}}$ vértebras direitas de 32 animais. Esse número de animais perfazia quatro repetições das combinações de interesse, ou seja, combinações dos quatro grupos genéticos e as duas dietas, citados anteriormente. As amostras de carne foram homogeneizadas após remoção da gordura externa.

Para determinação do teor de umidade em amostras de carne bovina utilizou-se a metodologia descrita pelo Instituto Adolfo Lutz (1985). Os teores de proteína, lipídios e resíduo mineral fixo foram determinados pelos métodos preconizados
Quadro 1. Composição da ração oferecida aos bovinos.

\begin{tabular}{|lcc|}
\hline \multicolumn{1}{|c}{ Ingredientes } & $\begin{array}{c}\text { Ração sem adição de } \\
\text { gordura protegida } \\
(\%) \text { D1 }\end{array}$ & $\begin{array}{c}\text { Ração com adição } \\
\text { de gordura } \\
\text { protegida (\%) D2 }\end{array}$ \\
$\begin{array}{l}\text { Feno de capim } \\
\text { braquiária } \\
\text { (brachiaria decunbens) }\end{array}$ & 40,00 & 40,00 \\
$\begin{array}{l}\text { Farelo de soja } \\
\text { desengordurado }\end{array}$ & 6,31 & \\
$\begin{array}{l}\text { Milho moído } \\
\text { Melaço em pó }\end{array}$ & 50,70 & 12,00 \\
Lipídios protegidos & 3,00 & 39,91 \\
\hline
\end{tabular}

Quadro 2. Médias dos teores de Matéria Seca (MS), Proteína Bruta (PB), Fibra em Detergente Neutro (FDN), Carboidratos Totais (CHOT), Nutrientes Digestíveis Totais (NDT), Extrato Etéreo (EE) ou lipídios e Matéria Mineral (MM) das dietas experimentais.

\begin{tabular}{|lccccccc|}
\hline \multicolumn{1}{|c}{ Dieta } & $\begin{array}{l}\text { MS } \\
(\%)\end{array}$ & PB & FDN & CHOT & $\begin{array}{c}\text { NDT } \\
\% \text { MS }\end{array}$ & EE & MM \\
$\begin{array}{l}\text { D1 (sem lipídios } \\
\text { protegidos) }\end{array}$ & 89,8 & 9,5 & 34,8 & 83,8 & 72,4 & 2,4 & 4,3 \\
$\begin{array}{l}\text { D2 (com lipídios } \\
\text { protegidos) }\end{array}$ & 90,2 & 11,0 & 34,4 & 77,5 & 72,8 & 6,2 & 5,3 \\
\hline
\end{tabular}

pela AOAC (1984). O teor de carboidratos foi calculado pela diferença percentual da soma dos teores de proteínas, lipídios totais, umidade e cinzas.

Para análise do perfil de ácidos graxos, utilizaram-se os métodos de extração de lipídios (BLIGH; DYER, 1959), esterificação (HARTMAN; LAGO, 1986) e cromatografia gasosa. Utilizou-se um cromatógrafo a gás (Shimadzu GC-17 A), equipado com injetor split/splitless (razão do split; 75:1), detector de ionização de chama e coluna capilar de sílica fundida SP-2560 SUPELCO (100 m; 0,25 mm e 0,2 $\mu \mathrm{m})$. Para a análise cromatográfica foi utilizado um gradiente de temperatura inicial de $170{ }^{\circ} \mathrm{C}$, prosseguindo com $2{ }^{\circ} \mathrm{C} /$ minuto até $215^{\circ} \mathrm{C}, 0,5^{\circ} \mathrm{C} /$ minuto até $225^{\circ} \mathrm{Ce} 1{ }^{\circ} \mathrm{C} /$ minuto até $240^{\circ} \mathrm{C}$, permanecendo por 10 minutos. Utilizaram-se as temperaturas de 250 e $270{ }^{\circ} \mathrm{C}$ para o injetor e o detector, respectivamente. Os fluxos de gás utilizados para a coluna foram de $0,49 \mathrm{~mL} /$ minuto e fluxo total de $61 \mathrm{~mL} /$ minuto. Os picos foram identificados e quantificados por comparação com padrões (189191A FAME MIX C4 - C24). Utilizou-se $1 \mu \mathrm{L}$ de amostra para injeção em cromatógrafo. A quantificação foi realizada por normalização e as porcentagens de área, transformadas em porcentagens de massa.

As concentrações de ferro e zinco foram determinadas por digestão nitro-perclórica (SARRUGE; HAAG, 1974), adaptada pelo laboratório de Solos do curso de Agronomia da Universidade Federal de Viçosa - UFV. As diferentes soluções obtidas foram analisadas por espectrofotometria de absorção atômica, em aparelho modelo GBC 908 AA.

Para a quantificação de colesterol total utilizou-se a extração de lipídios (FOLCH; LEES; SLOANE STANLEY, 1957), adaptada pela Faculdade de Ciências Farmacêuticas da Universidade de São Paulo - (FCF/USP). O preparo das amostras para injeção no cromatógrafo a gás (Shimadzu GC-17 A) foi realizado 
conforme Naeemi et al. (1995). Utilizou-se coluna capilar DB-1 (100 m; 0,25 mm e 0,2 $\mu \mathrm{m}$ ) e gradiente de temperatura inicial de $170{ }^{\circ} \mathrm{C}$, prosseguindo com $2{ }^{\circ} \mathrm{C} /$ minuto até $215^{\circ} \mathrm{C}$, $0,5^{\circ} \mathrm{C} /$ minuto até $225^{\circ} \mathrm{Ce} 1{ }^{\circ} \mathrm{C} /$ minuto até $240^{\circ} \mathrm{C}$, permanecendo por 10 minutos. Os picos foram identificados e quantificados por comparação com padrões de $5 \alpha$-colestane e colesterol. Utilizou-se $1 \mu \mathrm{L}$ de amostra para injeção em cromatógrafo. Utilizando-se curva de calibração composta pela razão entre as áreas do pico de colesterol em diferentes concentrações e do padrão interno (5 $\alpha$-colestane) versus as massas de colesterol correspondentes.

O experimento foi conduzido segundo um esquema fatorial (4 X 2) (quatro grupos genéticos $\times$ dois tipos de dietas), segundo delineamento inteiramente casualizado, com quatro repetições (exceto para o perfil de AG, que foi realizado com três repetições).

Os dados foram submetidos à análise de variância e quando a combinação entre os fatores foi significativa a $5 \%$ de probabilidade, a combinação foi desdobrada analisando-se um fator dentro dos níveis de outro fator, utilizando-se o teste de Tukey. As análises estatísticas foram desenvolvidas utilizando-se o programa SAEG, versão 7.1.

\section{Resultados e discussão}

Não foram encontradas diferenças nos teores de lipídios totais, proteína, carboidratos e umidade da carne bovina. Somente o teor de cinzas e de ferro foi afetado pela interação do tipo de dieta e grupo genético (Tabela 1).

$\mathrm{Na}$ Tabela 2 encontram-se os valores médios de lipídios totais (22,0 a $26,7 \%$ - base seca [BS]), proteína (63,2 a 69,5\% - BS), carboidratos (3,0 a 7,1 - BS), teores de umidade (63,4 a 71,3\%), ferro (2,8 a 4 mg. $\left.100 \mathrm{~g}^{-1}\right)$ e zinco $\left(6,3\right.$ a $\left.8,4 \mathrm{mg} \cdot 100 \mathrm{~g}^{-1}\right)$ da carne bovina proveniente de diferentes grupos genéticos e das duas dietas testadas.

O valor médio de lipídios do presente trabalho $(24,9 \% \mathrm{em}$ base seca) apresentou-se próximo ao encontrado por Madron et al. (2002), os quais relataram que novilhos recebendo dieta composta por 12,7 ou $25,6 \%$ de soja apresentaram $30,9 \%$ de lipídios (BS). Entretanto, mais recentemente, Padre et al. (2006) encontraram um valor ainda mais alto, 36,4\% em amostras de carne bovina de 3 diferentes grupos genéticos em pastagem.

O teor médio de proteína (BU) encontrado neste trabalho foi de 19,73\%, bem próximo ao valor encontrado por Torres et al. (2000), de 19,12\%. Entretanto Madron et al. (2002) verificaram uma média de $14,3 \%$ de proteína, em novilhos alimentados com dietas suplementadas com óleo de soja (12,7 e 25,6\% da dieta) por 111 dias. Esses valores sugerem que a suplementação da dieta animal, por si só, não influencia os depósitos protéicos, e que talvez o tempo do tratamento não foi longo o suficiente para aumentar estes depósitos.

A Tabela 3 mostra os quadrados médios do perfil de ácidos graxos e o teor de colesterol da carne bovina, tendo sido encontrada diferença apenas para os valores de AGPI, w-3 e relação $\mathrm{w}-6 / \mathrm{w}-3$, entre as dietas testadas.

A Tabela 4 apresenta as médias de ácidos graxos das amostras de carne bovina dos diferentes tratamentos.

Amostras de carne dos animais tratados com a dieta protegida apresentaram maior teor de AGPI $(5,24 \%)$ do que as amostras com dieta normal $(4,21 \%)$, mostrando que a incorpo-

Tabela 1. Resumo da análise de variância da composição centesimal das amostras de carne bovina em suas diferentes combinações.

\begin{tabular}{lcccccccc}
\hline Fonte de variação & GL & \multicolumn{5}{c}{ Quadrado médio } \\
\cline { 3 - 8 } & & Lipídios & Proteína & Carboidratos & Umidade & Cinzas & Ferro \\
\hline GG & 3 & $21,3835^{\text {ns }}$ & $28,3835^{\text {ns }}$ & $6,4841^{\text {ns }}$ & $16,1575^{\text {ns }}$ & $0,2728^{*}$ & $0,4832^{\text {ns }}$ & $8,8905^{\text {ns }}$ \\
Dieta & 1 & $24,4171^{\text {ns }}$ & $26,1514^{\text {ns }}$ & $2,2898^{\text {ns }}$ & $33,3120^{\text {ns }}$ & $1,7972^{\text {ns }}$ & $0,0397^{\text {ns }}$ & $0,6670^{\text {ns }}$ \\
GG X Dieta & 3 & $3,4829^{\text {ns }}$ & $4,2046^{\text {ns }}$ & $7,1945^{\text {ns }}$ & $32,2653^{\text {ns }}$ & $0,4272^{*}$ & $1,2909^{*}$ & $6,2100^{\text {ns }}$ \\
Resíduo & 24 & 15,5328 & 12,7521 & 3,0476 & 15,8296 & 0,1022 & 0,3516 & 3,0389 \\
CV (\%) & & 15,82 & 5,33 & 34,75 & 5,74 & 10,32 & 17,21 & 17,74 \\
\hline
\end{tabular}

${ }^{\star}$ Significativo a $5 \%$ de probabilidade pelo teste $F$; ns Não significativo a $5 \%$ de probabilidade pelo teste $F$; GL = graus de liberdade; e GG = grupos genéticos.

Tabela 2. Comparação da composição centesimal das amostras de carne bovina em suas diferentes combinações.

\begin{tabular}{|c|c|c|c|c|c|c|c|}
\hline Tratamentos & $\begin{array}{c}\text { Lipídios } \\
\left(\mathrm{g} .100 \mathrm{~g}^{-1}\right)^{1}\end{array}$ & $\begin{array}{l}\text { Proteínas } \\
\left(\mathrm{g} .100 \mathrm{~g}^{-1}\right)^{1}\end{array}$ & $\begin{array}{c}\text { Carboidratos } \\
\left(\mathrm{g} .100 \mathrm{~g}^{-1}\right)^{1} \\
\end{array}$ & $\begin{array}{l}\text { Umidade } \\
\left(\mathrm{g} .100 \mathrm{~g}^{-1}\right)\end{array}$ & $\begin{array}{c}\text { Cinzas } \\
\left(\mathrm{g} .100 \mathrm{~g}^{-1}\right)^{1}\end{array}$ & $\begin{array}{c}\mathrm{Fe} \\
\left(\mathrm{mg} .100 \mathrm{~g}^{-1}\right)^{1}\end{array}$ & $\begin{array}{c}\mathrm{Zn} \\
\left(\mathrm{mg} \cdot 100 \mathrm{~g}^{-1}\right)^{1}\end{array}$ \\
\hline R1D1 & 25,48 & 66,73 & 4,68 & 70,23 & 3,09 & 4,00 & 8,39 \\
\hline R1D2 & 26,68 & 63,23 & 7,10 & 69,57 & 2,97 & 2,77 & 6,29 \\
\hline R2D2 & 26,14 & 65,84 & 4,97 & 70,15 & 3,04 & 3,98 & 7,23 \\
\hline R3D1 & 21,95 & 69,55 & 5,20 & 68,57 & 3,28 & 2,92 & 8,23 \\
\hline R4D2 & 26,56 & 65,71 & 4,85 & 63,42 & 2,86 & 3,49 & 7,36 \\
\hline
\end{tabular}

${ }^{1}$ Dados expressos em base seca; R1D1 - Nelore alimentado com dieta composta por lipídios de origem vegetal sem proteção; R1D2 - Nelore alimentado com dieta composta por lipídios protegidos; R2D1 - F1 meio-sangue Nelore x Canchin alimentado com dieta composta por lipídios de origem vegetal sem proteção; R2D2 - F1 meio-sangue Nelore X Canchin alimentado com dieta composta por lipídios protegidos; R3D1 - F1 meio-sangue Nelore x Limousin alimentado com dieta composta por lipídios de origem vegetal sem proteção; R3D2 - F1 meiosangue Nelore $\mathrm{x}$ Limousin alimentado com dieta composta por lipídios protegidos; R4D1 - F1 meio-sangue Aberdeen Angus X Nelore alimentado com dieta composta por lipídios de origem vegetal sem proteção; e R4D2 - F1 meio-sangue Aberdeen Angus x Nelore alimentado com dieta composta por lipídios protegidos. 
Tabela 3. Resumo das análises de variância do perfil de ácidos graxos e teor de colesterol das amostras de carne bovina provenientes das diferentes combinações.

\begin{tabular}{|c|c|c|c|c|c|c|c|c|c|c|}
\hline \multirow[t]{2}{*}{ Fonte de variação } & \multicolumn{10}{|c|}{ Quadrado médio } \\
\hline & GL & $\mathrm{AGS}^{* *}$ & $\mathrm{AGMI}^{* * *}$ & $\mathrm{AGPI}^{* * * *}$ & $\begin{array}{l}\text { Relação } \\
\mathrm{P} / \mathrm{S}^{* * * * *}\end{array}$ & AGPI w-6 & AGPI w-3 & $w-6 / w-3$ & Colesterol & pni $^{* * * * * *}$ \\
\hline GG & 3 & $7,0015^{\mathrm{ns}}$ & $13,0563^{\mathrm{ns}}$ & $0,4317^{\mathrm{ns}}$ & $0,0001^{\mathrm{ns}}$ & $0,6782^{\mathrm{ns}}$ & $0,0011^{\mathrm{ns}}$ & $10,84^{\mathrm{ns}}$ & $68,8388^{\mathrm{ns}}$ & $1,0215^{\mathrm{ns}}$ \\
\hline GG $\times$ Dieta & 3 & $5,3422^{\text {ns }}$ & $3,9225^{\mathrm{ns}}$ & $0,6309^{\text {ns }}$ & $0,0002^{\text {ns }}$ & $0,2610^{\mathrm{ns}}$ & $0,0009^{\text {ns }}$ & $5,75^{\mathrm{ns}}$ & $108,9900^{\text {ns }}$ & $0,6809^{\text {ns }}$ \\
\hline Resíduo & 16 & 5,6266 & 6,3147 & 0,7849 & 0,0001 & 0,4589 & 0,0011 & 12,78 & 50,2598 & 0,5209 \\
\hline
\end{tabular}

${ }^{\star}$ Significativo a $5 \%$ de probabilidade pelo teste $F ;{ }^{\text {ns }} \mathrm{Não}$ significativo a $5 \%$ de probabilidade pelo teste $F ;$ GL $=$ graus de liberdade; GG $=$ grupos genéticos; ${ }^{* *} \mathrm{AGS}=\mathrm{C} 8: 0+\mathrm{C} 10: 0+\mathrm{C}$ $11: 0+C 12: 0+C$ 13:0 + C 14:0 + C 16:0 + C 17:0 + C 18:0 + C 20:0 + C 22:0 + C 24:0; ${ }^{* * * A G M I ~=~ C ~ 14: 1 ~+~ C ~ 16: 1 ~+~ C ~ 17: 1 ~+~ C 18: 1 ~ 11 ~+~ C ~ 18: 1 ~ 9 c ~+~ C ~ 20: 1 ; ~ * * * * A G P I ~=~ C ~ 18: 2 ~ 6 c ~ w-6 ~}$ + C 18:3 w-6 + C 20:2 w-6 + C 20:3 w-6 + C 20:4 w-6 + C 18:3 w-3 + C 20:5 3c w-3 + C 22:6 w-3 + C 18:2 w-9 + C18.2 9c11t + C18.2 10t12c; *****P/S = (ácido linoléico) / (C 8:0 + C 10:0 + C 11:0 + C 12:0 + C 13:0 + C 14:0 + C 16:0 + C 17:0 + C 18:0 + C 20:0 + C 22:0 + C 24:0); e***** Picos não identificados (ausentes no padrão).

Tabela 4. Perfil de ácidos graxos das amostras de carne bovina dos diferentes tratamentos.

\begin{tabular}{ccccccccc}
\hline Combinações $^{* * *}$ & AGS (\%) & AGMI (\%) & AGPI (\%) & Relação P/S* & AGPI w-6 & AGPI w-3 & w-6/w-3 & Colesterol (mg.100 g-1 $)^{\star *}$ \\
\hline R1D1 & 46,73 & 43,80 & 4,48 & 0,070 & 3,83 & 0,19 & 19,63 & 48,77 \\
R1D2 & 47,28 & 42,13 & 5,27 & 0,071 & 3,76 & 0,12 & 30,07 & 37,44 \\
R2D1 & 48,48 & 40,84 & 4,69 & 0,064 & 3,64 & 0,20 & 18,40 & 41,25 \\
R2D2 & 45,87 & 42,83 & 5,01 & 0,067 & 3,48 & 0,13 & 25,84 & 36,93 \\
R3D1 & 48,96 & 41,60 & 3,94 & 0,056 & 3,28 & 0,16 & 21,29 & 36,46 \\
R3D2 & 45,08 & 42,94 & 5,79 & 0,080 & 4,01 & 0,14 & 27,87 & 43,01 \\
R4D1 & 45,59 & 44,61 & 3,75 & 0,056 & 3,06 & 0,15 & 19,73 & 47,75 \\
R4D2 & 44,23 & 45,71 & 4,90 & 0,060 & 2,99 & 0,11 & 25,78 & 43,22 \\
\hline
\end{tabular}

${ }^{\star} \mathrm{P} / \mathrm{S}=($ ácido linoléico $) /\left(\mathrm{C}\right.$ 8:0 + C 10:0 + C 11:0 + C 12:0 + C 13:0 + C 14:0 + C 16:0 + C 17:0 + C 18:0 + C 20:0 + C 22:0 + C 24:0); ${ }^{* *}$ Valores expressos em base úmida; ${ }^{* * * R 1 D 1 ~-~ N e l o r e ~ a l i-~}$ mentado com dieta composta por lipídios de origem vegetal sem proteção; R1D2 - Nelore alimentado com dieta composta por lipídios protegidos; R2D1 - F1 meio-sangue Nelore $x$ Canchin alimentado com dieta composta por lipídios de origem vegetal sem proteção; R2D2 - F1 meio-sangue Nelore X Canchin alimentado com dieta composta por lipídios protegidos; R3D1 - F1 meio-sangue Nelore $x$ Limousin alimentado com dieta composta por lipídios de origem vegetal sem proteção; R3D2 - F1 meio-sangue Nelore x Limousin alimentado com dieta composta por lipídios protegidos; R4D1 - F1 meio-sangue Aberdeen Angus X Nelore alimentado com dieta composta por lipídios de origem vegetal sem proteção; e R4D2 - F1 meio-sangue Aberdeen Angus x Nelore alimentado com dieta composta por lipídios protegidos.

ração de ácidos graxos foi diferenciada. Enser et al. (1999), Leth, Ovesen e Hansen (1998) e Rule et al. (2002) encontraram teores médios mais baixos, de 4,06, 3,3 e 5,04 mg de AGPI.100 $\mathrm{mg}^{-1}$ de AG, respectivamente, demonstrando uma maior eficiência na deposição lipídica pelo uso de lipídios protegidos, uma vez que estes estudos não utilizaram esta tecnologia.

Muitos trabalhos têm relatado que a suplementação com fontes de AGPI ou AGMI na alimentação de bovinos tem sido incorporada na carne bovina eficientemente(ENSER et al., 1999; MOLONEY et al., 2001; PALMIQUIST, 1991). Um exemplo de sucesso pode ser observado no trabalho de Scollan et al. (2001), onde utilizaram na alimentação de bovinos óleo de linhaça, que é rico em ácido $\alpha$-linolênico, resultando em um aumento de $100 \%$ na concentração deste AG no músculo bovino. Apesar desse incremento, observa-se que os valores ainda são muito baixos em relação às cotas diárias recomendadas. Entretanto, este novo recurso na tecnologia de alimentos, quando somado a uma alimentação equilibrada, pode ser de grande valor para alcançarmos as recomendações de ingestão diária de AGI e AGPI.

Outro resultado importante neste trabalho foi que a dieta protegida (D2) propiciou um menor teor de w-3 $(0,13 \%)$ na carne dos animais, em relação a D1 $(0,18 \%)$, favorecendo o aumento da relação w-6/w-3. A recomendação atual para esta relação é de 5 a 10:1 (RDA, 2005). Esses valores mais baixos de w-3 para D2 podem ser atribuídos também pelo fato de que esta dieta teve maior suplementação de soja, a qual é pobre em w-3. Este pode ser um dos motivos pelos quais animais recebendo alimentação em pastagem apresentaram teores bem mais elevados de w-3 na carne, 1,03 e 2,9\%, respectivamente (ENSER et al., 1996; RULE et al., 2002). Apesar de saber que o consumo de AGPI w-3 reduz o risco de doenças cardiovasculares, grande porcentagem da população (mais de 65\%) não ingere peixe, que é uma boa fonte nutricional desse componente (ROCHE, 1999), por seu custo ou por não fazer parte do hábito alimentar da região.

Os valores médios de colesterol na carne bovina variaram de 36,46 a 48,77 mg. $100 \mathrm{~g}^{-1}$ de carne. Na Tabela 3 pode-se verificar que os diferentes grupos genéticos, dietas e a interação GG $x$ dieta não afetaram o teor de colesterol na carne bovina. Valores semelhantes para colesterol foram encontrados no estudo de Padre et al. (2006), 46, 44 a 48,29 mg.100 g g $^{-1}$, entretanto, nesse trabalho houve diferença significativa entre as raças testadas. Segundo Bragagnolo e Rodriguez-Amaya (1995), valores de colesterol em carne bovina entre 55 e 65 mg. $100 \mathrm{~g}^{-1}$ são os mais típicos na literatura, porém, valores mais discrepantes podem ser atribuídos aos procedimentos analíticos empregados.

Ainda segundo os mesmos autores, a carne bovina tem valores de colesterol próximos aos de outras carnes, como filé de peito de frango cru (58 mg. $100 \mathrm{~g}^{-1}$ ); coxa e sobrecoxa sem 
pele cruas ( $80 \mathrm{mg} .100 \mathrm{~g}^{-1}$ ); lombo suíno cru (49 mg.100 g-1); e filé de peito de frango assado $\left(71 \mathrm{mg} \cdot 100 \mathrm{~g}^{-1}\right)$. Segundo Stipanuk (2000), a contribuição das carnes na ingestão de colesterol diário é de um terço à metade da recomendação diária $(300 \mathrm{mg} / \mathrm{dia})$. Entretanto, a produção de uma carne magra propicia um aumento proporcional do teor de colesterol, sendo que a maioria desse colesterol é proveniente das membranas celulares e estruturas intracelulares; porém, o lipídio intramuscular possui um baixo teor de colesterol (SWEETEN et al., 1990).

Segundo Sweteen et al. (1990), carnes magras, de modo geral, podem ser consumidas normalmente por pessoas que seguem uma alimentação saudável. A educação nutricional terá papel primordial neste contexto, para que os indivíduos saibam como selecionar, preparar e consumir alimentos mais saudáveis, garantindo assim que sua dieta esteja dentro dos padrões preconizados pelos órgãos de saúde.

\section{Conclusões}

Verificou-se que a utilização de uma dieta com lipídios protegidos favoreceu uma carne bovina com maior teor de AGPI. Entretanto, mais estudos são necessários para que seja avaliado qual teor de AGPI garante efeito hipocolesterolemiante e se o sal cálcico de ácido graxo está garantindo uma proteção efetiva aos AGPI ou se está propiciando o aparecimento de ácidos graxos intermediários na gordura destes animais, tais como: ácido linoléico conjugado (mistura de isômeros geométricos e de posição do ácido linoléico) e ácidos graxos trans (mistura de ácido transvacênico ou rumênico e ácido elaídico). Sendo que o primeiro está envolvido com a proteção ao desenvolvimento de câncer, aterosclerose, diabetes e obesidade, e o segundo associado ao aumento da prevalência de doenças cardiovasculares.

\section{Referências bibliográficas}

ABNP - Associação Brasileira de Novilho Precoce. Disponível em: <http://www.novilhoprecocebrasil.com.br>. Acesso em: 2007.

ABULARACH, M. L. S.; ROCHA, C. E.; FELÍCIO, P. E. Características de qualidade do contrafilé (M. L. Dorsi) de touros jovens da raça nelore. Ciência e Tecnologia de Alimentos, v. 18, n. 2, p. 205-210, 1998.

ANDERSON, B. A.; LAUDERDALE, J. L.; HIKE, I. M. Composition of foods: beef products - raw, processed, prepared. n. 8-13. USDA Agriculture Handbook, 1986.

AOAC. Official method of analysis. Washington, D.C., 1984.

BELURY, M. A. Dietary conjugated linoleic acid in health: physiological effects and mechanisms of action. Annual Review Nutrition, v. 22, n. 2, p. 505-531, 2002.

BHATTACHARYA, A. et al. Biological effects of conjugated linoleic acids in health and disease. The Journal of Nutritional Biochemistry, v. 17, n. 12, p. 789-810, 2006.

BLIGH, E. G.; DYER, W. I. A rapid method of total lipid extraction and purification. Canadian Journal of Biochemistry and Physiology, v. 37, n. 8 , p. 911-917, 1959.

BONANOME, A.; GRUNDY, S. M. Effect of dietary stearic acid on plasma cholesterol and lipoprotein levels. The New England Journal of Medicine, v. 318, n. 19, p. 1244-1248, 1988.
BRAGAGNOLO, N.; RODRIGUES-AMAYA, D. B. Teores de colesterol em carne suína e bovina e efeito do cozimento. Ciência e Tecnologia de Alimentos, v. 15, n. 1, p. 11-17, 1995.

COSGROVE, M.; KIELY, M.; FLYNN, A. The contributions lof meat to nutrient intakes in Irish men and women of different ages. In: CONGRESSO BRASILEIRO DE CIÊNCIA E TECNOLOGIA DE CARNESEDITED BY, 2001, Campinas. Anais... Campinas: SBCTA, p.152, 2001.

COSTA, A. G. V.; BRESSAN, J.; SABARENSE, C. M. Ácidos Graxos Trans: Alimentos e Efeitos na Saúde. Archivos Latinoamericanos de Nutrición, v. 56, n. 1, p. 12-21, 2006.

DE LA TORRE, A. et al. Factors influencing proportion and composition of CLA in beef. Meat Science, v. 73, n. 2, p. 258-268, 2006.

DEMEYER, D.; DOREAU, M. Targets and procedures for altering ruminant meat and milk lipids. Procedings of the Nutrition Society, v. 58, n. 3, p. 593-607, 1999.

ENSER, M. et al. Fatty acid content and composition of English beef, lamb and pork at retail. Meat Science, v. 42, n. 4, p. 443-456, 1996.

ENSER, M. et al. Fatty acid content and composition of UK beef and lamb muscle in relation to production system and implications for humans nutrition. Meat Science, v. 49, n. 3, p. 329-341, 1998.

ENSER, M. et al. Effect of dietary lipid on the content of conjugated linoleic acid (CLA) in beef muscle. Animal Science Journal, v. 69, n. 1, p. 143-146, 1999.

FAO - Food And Agriculture Organization Of The United Nations. Disponível em:<http://www.fao.org/>. Acesso em: 2006.

FOLCH, J.; LEES, M.; SLOANE STANLEY, G. H. A simple method for the isolation and purification of total lipides from animal tissues. The Journal of Biological Chemistry, v. 226, n. 1, p. 497-509, 1957.

FRANCO, G. Tabela de Composição Química de Alimentos. 9 ed. São Paulo: Atheneu, 1992.

GEBAUER, S. K. et al. n-3 Fatty acid dietary recommendations and food sources to achieve essentiality and cardiovascular benefits. The American Journal of Clinical Nutrition, v. 83, n. 6, p. S1526-1535, 2006.

GROFF, J. L.; GROPPER, S. S.; HUNT, S. M. Advanced nutrition and human metabolism. 2 ed. New York: Hardcover, 1995.

HARTMAN, L.; LAGO, R. C. A. Rapid preparation of fatty acids methyl esters. Laboratory Pratices, v. 22, n. 6, p. 475-476, 1986.

IBGE. Estudo da Despesa Familiar - Quadro de Composição de Alimentos. Rio de Janeiro, 1981.

INSTITUTO ADOLFO LUTZ. Normas analíticas - Métodos químicos e físicos para análise de alimentos. São Paulo, 1985.

JIMÉNEZ-COLMENERO, F.; CARBALLO, J.; COFRADES, S. Healthier meat and meat products: their role as functional foods. Meat Science, v. 59, n. 1, p. 5-13, 2001.

JUNQUEIRA, J. O. Qualidade das carcaças de bovinos jovens, machos e fêmeas, cruzadas marchigiana vs. Nelore, terminados em confinamento. Pirassununga, 1996. Dissertação - (Mestrado em Zootecnia), Universidade de São Paulo.

KRITCHEVSKY, D. Effects of triglyceride structure on lipid metabolism. Nutrition Review, v. 46, n. 5, p. 177-181, 1988.

LETH, T.; OVESEN, L.; HANSEN, K. Fatty acid composition of meat from ruminants, with special emphasis on trans fatty acids. The American Oil Chemists Society, v. 75, n. 8, p. 1001-1005, 1998.

LIMA, F. et al. Ácidos graxos e doenças cardiovasculares: uma revisão. Review Nutrition, v. 13, n. 2, p. 73-80, 2000. 
LIRA, G. M. et al. Determinação de lipídios e colesterol em carnes bovina e suína comercializadas em Maceió. Journal of the Brazilian Chemical Society, v. 21, n. 1, p. 7-16, 2001.

MADRON, M. S. et al. Effect of extruded full-fat soybeans on conjugated linoleic acid content of intramuscular, intermuscular, and subcutaneous fat in beef steers. Journal Animal Science, v. 80, n. 4, p. 1135-1143, 2002.

MAHAN, L. K.; ESCOTT-STUMP, S. Alimentos Nutrição e Dietoterapia. 11 ed. São Paulo: Roca, 2005.

MOLONEY, A. P. et al. Producing tender and flavoursome beef with enhanced nutritional characteristics. Procedings Nutrition Society, v. 60 , n. 2, p. 221-229, 2001.

NAEEMI, E. D. et al. Rapid and simple method for determination of cholesterol in processed food. The American Oil Chemists Society, v. 78, n. 6, p. 1522-1525, 1995.

PADRE, R. D. G. et al. Analysis of fatty acids in Longissimus muscle of steers of different genetic breeds finished in pasture systems. Livestock Science, v. 110, n. 1-2, p. 57-63, 2007.

PALMIQUIST, D. L. Influence of source and amount of dietary fat on digestibility in lactating cows. Journal of Dairy Science, v. 74, n. 4, p. 1354-1360, 1991.

PHILLIPSON, B. E. et al. Reduction of plasma lipids, lipoproteins and apoproteins by dietar fish oils in patients with hipertriglyceridemia. The New England Journal of Medicine, v. 31, n. 2, p. 1210-1216, 1985.

RDA. Dietary Reference Intakes for Energy, Carbohydrate. Fiber, Fat, Fatty Acids, Cholesterol, Protein, and Amino Acids. Disponível em:<www.nap.edu>. Acesso em: 2005.

ROCHE, H. M. Unsaturated fatty acids. Proceedings Nutrition Society, v. 58, n. 2, p. 397-401, 1999.

RULE, D. C. et al. Comparison of muscle fatty acid profiles and cholesterol concentrations of bison, beef cattle, elk, and chicken. Journal Animal Science, v. 80, n. 5, p. 1202-1211, 2002.
SARRUGE, J. R.; HAAG, H. P. Análises químicas em plantas. Piracicaba: ESALQ - USP: Edusp, 1974.

SBAN - Sociedade Brasileira de Alimentação e Nutrição. Disponível em: $<$ http://www.sban.com.br/ $>$. Acesso em: 2006.

SCHMID, A. et al. Conjugated linoleic acid in meat and meat products: A review. Meat Science, v. 73, n. 1, p. 29-41, 2006.

SCOLLAN, N. et al. Innovations in beef production systems that enhance the nutritional and health value of beef lipids and their relationship with meat quality. Meat Science, v. 74, n. 1, p. 17-33, 2006.

SCOLLAN, N. D. et al. Manipulating the fatty acid composition of muscle and adipose tissue in beef cattle. British Journal of Nutrition, v. 85, n. 1, p. 115-124, 2001.

STIPANUK, M. H. Biochemical and physiological aspects of human nutrition. 1 ed. New York: W. B. Saunders, 2000.

SWEETEN, M. K. et al. Lean beef: impetus for lipid modifications. Journal of the American Dietetic Association, v. 90, n. 1, p. 87-92, 1990.

TANAKA, K. Occurrence of conjugated linoleic acid in ruminant products and its physiological functions. Animal Science Journal, v. 76, n. 4, p. 291-303, 2005.

TEIXEIRA, N. F. Nutrição clínica. 1 ed. Rio de Janeiro: Guanabara Koogan, 2003.

TORRES, E. A. F. S. et al. Composição Centesimal e Valor Calórico de Alimentos de Origem Animal. Ciência e Tecnologia de Alimentos, v. 20, n. 2, p. 145-150, 2000.

WOOD, J. D.; ENSER, M. Factors influencing fatty acids in meat and the role of antioxidants in improving meat quality. British Journal of Nutrition, v. 78, Suppl 1, p. S49-60, 1997.

YAKULT, S. A. Indústria e Comércio - Suplemento. Nova fonte de energia para gado leiteiro. Gordura protegida (Rumem By-Pass Fat). Tokyo: Central Institute for Microbiological Research, 2000. 